\title{
International Journal of Business and Administrative Studies
}

volume 6 issue 2 pp. 73-85 doi: https://dx.doi.org/10.20469/ijbas.6.10002-2

\section{Consumer Trust Towards Content Marketing of Food \& Beverage Businesses on Instagram: Empirical Analysis of Taiwanese and Singaporean Consumers}

\author{
Verona Mentari Mohammad* \\ Faculty of Economics and Business, University of Groningen, Groningen, Netherlands
}

\begin{abstract}
Nowadays, food and beverage businesses need some adjustments regarding their marketing strategy as people's lifestyle, and dietary patterns are varied. One of the marketing strategies on social media which local restaurant marketers can adopt is content marketing. However, content marketing will not work until trust is established (Newman, 2014). Marketers must ensure that the contents are genuine and transparent enough to develop trust (Kee \& Yazdanifard, 2015). This study aims to examine the effect of product transparency on consumer trust to increase the effectiveness of content marketing and investigate whether one of Hofstede's cultural dimensions, uncertainty avoidance, can be the moderator of this relationship. The valid respondents of the online survey were 111 Taiwanese and Singaporean. It was revealed that product transparency positively influences consumer trust, and uncertainty avoidance cannot be the significant moderator of this relationship. Furthermore, an additional analysis provided evidence where uncertainty avoidance has a negative influence on consumer trust. Therefore, providing transparent information regarding food products in content marketing would help to increase the effectiveness of local restaurant's marketing strategy through social media, and recognizing the cultural dimensions of where the business operates will give an initial hint of the consumer's propensity to trust. The importance of this research is to recognize the possible factor that can help to increase the effectiveness of content marketing for food and beverage businesses, specifically for local restaurants. Marketers need to evaluate their strategy depending on the consumers' perception of trust and transparency and choose their content strategy appropriately based on the trust beliefs of the consumers of a country where the business will be performed.
\end{abstract}

Keywords: Product transparency, uncertainty avoidance, consumer trust, content marketing, local restaurant

Received: 20 November 2019; Accepted: 28 January 2020; Published: 20 April 2020

\section{INTRODUCTION}

"Global food production and consumption patterns have evolved over the past decades" (Hamadeh, 2017). It happened due to increasing income and improved consumer perception regarding the quality and safety of food products, particularly in emerging markets (Baker \& Friel, 2016). Nowadays, food and beverage businesses need some adjustments regarding their marketing strategy as the dietary patterns of people are more varied, especially with the evolving trend of a healthy lifestyle. In this study, the concept of food and beverage businesses will be mainly focused on local restaurants. Based on the definition from Local Saute (n.d.), a local restaurant defined as an independent restaurant that is not a part of a corporate chain, and it serves customers in a specific city or area. Unlike the fast-food company that might have an enormous budget for advertising their products through television advertisements, a local

\footnotetext{
${ }^{*}$ Correspondence concerning this article should be addressed to Verona Mentari Mohammad, Faculty of Economics and Business, University of Groningen, Groningen, Netherlands. E-mail: veronamentari@yahoo.com

(c) 2020 The Author(s). Published by KKG Publications. This is an Open Access article distributed under a Creative Commons AttributionNonCommercial-NoDerivatives 4.0 International License.
} 
restaurant is one of the businesses in the food and beverage industry that markets their product dominantly through social media since it is less expensive. Food and beverage executives recognize the significant impact that digital, social, and mobile technologies have on business growth (Green Hasson \& Janks, 2013). One of the marketing strategies on social media which local restaurant marketers can adopt is content marketing. The purpose of content marketing is to share valuable information about the products consumed by consumers (Kee \& Yazdanifard, 2015). Content marketing is different compared to influencer marketing since it does not rely on novel information contributors who can affect people's behavior and attitudes (Liu et al., 2015). Rowley (2008) defined digital content marketing as a management process that is accountable for identifying and satisfying the needs of customers by delivering the content through electronic channels in order to gain profit. Unfortunately, there are still few local restaurant marketers that have embraced content marketing because most of them are more concerned with the operations and unaware with other matters involved (Walter, 2015). Whereas content marketing strategy through social media enables businesses to become more visible, gain consumers' trustworthiness and creates brand awareness (Du Plessis, 2015; Kitdumrongthum \& Thechatakerng, 2018).

Instagram is one of the most popular social media that has become more valuable for food and beverage marketing than most websites. According to L2 Research Firm, Instagram had the highest number of engagements and conversion of browsers to shoppers (Gartner L2, 2014). Therefore, Instagram is an excellent platform for food and beverage businesses to spread information about their products. However, from $90 \%$ of B2C marketers who used content marketing, only $32 \%$ considered themselves competent (Pulizzi \& Handley, 2014).

A content marketing strategy that able to depict a more robust understanding of the consumers is feasible to establish and maintain consumer trust (Doyle, 2019). However, gaining consumer trust towards a content marketing strategy in social media is not that easy. Most of the time, a content marketing strategy will not work until trust is established, which therefore leads to adequate headway to trust-building efforts (Bilog, 2017; Newman, 2014). Marketers must ensure that the contents are genuine and transparent enough to develop trust (Kee \& Yazdanifard, 2015). Hence, product transparency is assumed to influence consumer trust while perceiving content marketing on social media.

Moser, Schaefers, and Meise (2012) argued that product transparency influences consumer trust in the food retailing industry. Furthermore, Pan (2014) has mentioned that there is a significant relationship between transparency and trust in the cosmetic industry as consumers are now relatively more careful about buying products concerning their health and safety. Therefore, this research contributes to the prior study by Pan (2014) through further investigating the product transparency factor for the implication of the B2C trust problem in real market conditions, specifically for the content marketing of local restaurants. According to Pan (2014), transparency is not a prominent issue that only occurs in the cosmetics industry, which therefore leads to the verification of whether the same effect will also occur in the food and beverage industry even the offered products are entirely different compared to the cosmetics industry.

As the researcher will analyze the comparison between consumers from two different nationalities, which are Taiwanese and Singaporean, therefore incorporating one of the cultural dimensions is useful in order to know the differences of the consumers' perception based on Hofstede's Uncertainty Avoidance Index (UAI). Doney, Cannon, and Mullen (1998) indicated that uncertainty avoidance has a positive correlation with the trust development process. According to Brown, Field, and Wessels (2006), uncertainty avoidance moderates the relationship between trust and intention to use online shopping. However, in this study, the factor 'perceived usefulness' will be replaced by product transparency. This study also contributes to prior research by Brown et al. (2006) since there are still few studies that explored the link between uncertainty avoidance and trust. Therefore, the uncertainty avoidance level will be incorporated to give a piece of evidence if there is a cultural dimension that would moderate the influence of product transparency on consumer trust towards content marketing. Hence, the research question is, "What is the effect of product transparency on consumer trust towards content marketing of local restaurants on Instagram, and how can this relationship be moderated by the uncertainty avoidance level of one's nationality?". The importance of this research is to recognize the possible factor that can help to increase the effectiveness of content marketing for food and beverage businesses, specifically for local restaurants. Marketers need to evaluate their strategy depending on the consumers' perception of trust and transparency and to choose their content strategy appropriately based on the trust beliefs of the consumers of a country where the business will be performed. The next section will explain the theoretical framework of the variables. On the result, hypotheses and a conceptual model will be proposed. Following the theoretical framework, the methodology of this study will be illustrated, and the results of the analysis will be reported. Before the conclusion part, a detailed discussion of the results and a general discussion of the whole study will be provided as well as the 
implications, limitations, and future research.

\section{THEORETICAL FRAMEWORK}

\section{Dependent Variable: Consumer Trust}

Trust can be defined as "a willingness to rely on an exchange partner in whom one has confidence" (Moorman, Zaltman, \& Deshpande, 1992). Consumer trust has a significant influence on consumers' purchasing decisions (Kim, Ferrin, \& Rao, 2008). However, the increasing amount of food safety scandals such as the use of synthetic chemicals leads to higher risk perceptions (Chen, 2008). When consumer's decision making is done virtually, consumers are vulnerable to incomplete and inaccurate information provided by marketers (Lee, 1998).

Digital content marketing intends to encourage consumer brand perceptions and sales. It does so by developing consumer engagement, trust, and relationships, which are designed to cultivate sales indirectly and in the long run (Hollebeek \& Macky, 2019). Trust, one of the aims of digital content marketing, is a significant element in the relationship that exists between a company and its customers (Arnott \& Wilson, 2007). Trust is the most critical factor in marketing success (Arnott, Wilson, \& Sichtmann, 2007). Trust consists of two different dimensions, which are cognitive trust and affective trust (Kang \& Ogawa, 2017; Moorman et al., 1992). In this research, the researcher will mainly focus on cognitive trust as it is one of the dimensions that is the most coherent with the term consumer trust in content marketing.

Cognitive-based trust defined as consumer confidence or willingness to rely on the competence and reliability of a business (Moorman et al., 1992; Rempel, Holmes, \& Zanna, 1985). It is a kind of trust which arises from an accumulated comprehension that allows one to make predictions with a certain level of credence, about the possibility that a focal partner will fulfill its obligations (Johnson \& Grayson, 2005). To find out the gap within the effectiveness of content marketing on Instagram, the researcher needs to perform a further study about the factor that would have an effect on the consumers' tendencies to trust the content marketing of local restaurants.

\section{Independent Variable: Product Transparency}

Product transparency can be interpreted as the complete disclosure and publicity of information in respect of product ingredients, product attributes, and production processes (Pan, 2014). Moreover, transparency has become a new method for many firms to reach their target consumers (Granados, Gupta, \& Kauffman, 2010). Kee and Yazdanifard (2015) argued that trust could be built, and customer loyalty can be maintained through content marketing that provides real and transparent information. Hustvedt and Kang (2013) implied that consumers' perception plays a critical role in building consumer trust, notably concerning on corporation's efforts to be transparent about the production. As consumers request for stronger product transparency, businesses are more likely to take on several communication efforts to take the opportunity from customers that appear to be loyal to companies that satisfy their desires (Moser et al., 2012). Transparency has vast implications concerning the disclosure of information and honesty to consumers, which leads the company to use transparency to build trust (The Hartman Group, 2015).

Consumer health awareness is augmenting by dint of the increasing availability of health information, along with the population aging and increased risk of diseases caused by lifestyle (Kearney, 2010). According to Label Insight Food Revolution Study (2016), 53 percent of the total respondents said that they consume the foods based on specific dietary. The consumer distrust has dispersed to restaurants, as the desire for honesty and openness in food ingredients and production increases (Benjamin, 2018). Consumers with allergens and dietary restrictions, including special diets, religious, and lifestyle choices, will prefer businesses that pay more attention to cater the consumer needs (Jones, 2016). Moreover, the current technological culture creates the inclination for transparency, where information is easy to access, and expectations for open source is increasing (The Hartman Group, 2015).

A study from Pan (2014) suggested that a highly strong relationship between product transparency and brand trust was found in her research. However, this study was limited only to cosmetic products. Cosmetics are products used for "cleanse, protect, and change the appearance of external body parts" (Australian Academy of Science, n.d), the perception of product transparency in food and beverage industry, specifically in local restaurants, is assumed to be more salient since it includes products that will be eaten and linked to internal health concerns. Therefore, the researcher needs to confirm whether the same effect also occurred in the food and beverage industry.

H1: Product transparency positively influences the consumer trust towards content marketing of local restaurants on 
Instagram.

\section{Moderator: Hofstede's Cultural Dimension-UAI}

When buying behavior involves the risks perceived by consumers, they would be willing to gather as much information as possible before buying to avoid taking risks (Pan, 2014). The more risks have been perceived by consumers, the less likely they will trust the brand of the products (Rampl, Eberhardt, Schütte, \& Kenning, 2012). Moreover, the perception of risks might be affected by the individual's national culture. Uncertainty avoidance is one of the cultural dimensions that was firstly introduced by Hofstede (1984). According to Hofstede (1993), uncertainty avoidance is the extent to which people in a country feel structured situations are preferable rather than the unstructured one. The cultural values dissimilarity across nations results in variations in people's cognitive functioning (McCort \& Malhotra, 1993).

According to the UAI Values for 50 Countries and Three Regions table that was made by Hofstede (2001), Taiwan is in the 26th rank, while Singapore is in 53rd place. Singapore has the lowest index of 8, while Taiwan has a high index of 69 (Hofstede, 2001). "The important characteristic of Taiwanese culture is the high level of uncertainty avoidance, which results in a high level of technology anxiety and a low level of self-efficacy" (Trappey, Trappey, \& Mulaomerovic, 2016). For instance, businesses in Taiwan tend to be more formal with comprehensive rules, and more focus on tactical operations rather than strategy (Tsai, 2009). According to the study made by Pheng and Yuquan (2002) in Singapore, ambiguous situations do not make Singaporean feel menaced. Moreover, this study also concluded that people in Singapore want to take risks. In Singapore, innovators experience independence from the rules, and innovation is welcome (Polevikova, 2013).

Prior research has stated the relationship between uncertainty avoidance and trust, as "people in cultures with high uncertainty avoidance might have a stronger reaction on negative trustworthiness attributes when they make a purchase decision" (Chong, 2003), which means that the higher the uncertainty avoidance level of one's culture, the lower the intention to trust a business. Moreover, according to the results from Brown et al. (2006), uncertainty avoidance has a moderating influence on the relationship between trust and the intention to use online shopping. Therefore, the researcher can assume that the UAI influences consumers' trust. However, it still needs to be studied further, whether it can also moderate the relationship between product transparency and consumer trust. To sum up, a person from a country with a higher UAI would solicit greater product transparency to escalate their trust towards the marketing strategy of local restaurants on Instagram.

H2: The higher the UAI of a country, the stronger the influence of product transparency on consumer trust towards content marketing of local restaurants on Instagram.

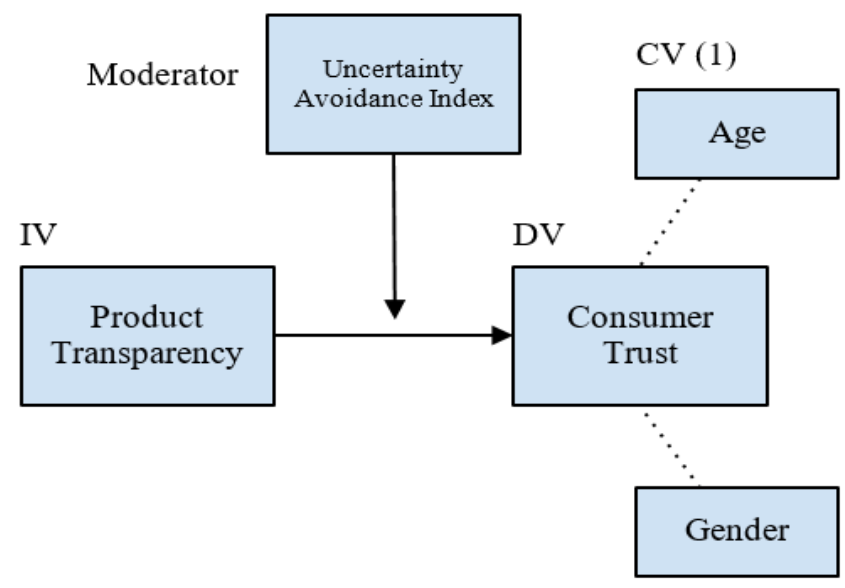

CV (2)

Figure 1 Conceptual Model

Based on the hypotheses that were mentioned before, the researcher can formulate the conceptual model, which can be seen in Figure 1. As stated in the theoretical framework, product transparency has a positive influence on consumer trust. Moreover, UAI moderates the influence of product transparency on consumer trust, since the culture of one's 
nationality can differentiate the way a person perceived risk. For the control variables, age and gender are included since there is a small possibility that these variables might influence the results. Age was chosen as one of the control variables since older consumers have a preference for long-established brands and have built the habits of buying such brands (Lambert-Pandraud \& Laurent, 2010). Gender was also included because "women were more likely than men to maintain trust in the face of repeated untrustworthy actions" (Haselhuhn, Kennedy, Kray, Van Zant, \& Schweitzer, 2015). As there were some arguments from prior research about the correlation of both variables to consumer trust, therefore age and gender were ruled out as an alternative explanation since the researcher considered them irrelevant for the research problem. The researcher did not expect both variables to affect the result of the study.

\section{METHODOLOGY}

\section{Research Design and Sample}

The data collection was conducted through Qualtrics online survey and distributed digitally via WhatsApp and Line. The online survey was targeted to Taiwanese who live in Taipei and Singaporeans who live in Singapore. There were no age restrictions for this survey since the researcher intended to acquire the perceptions across generations. The online survey was conducted only in English, as the Taiwanese are known for moderate proficiency with Taipei as the highest English proficiency by region, while Singaporeans are notable with very high English proficiency (English First, 2019). The online survey was distributed through the snowball sampling method. 131 respondents were gathered, consisting of 58 Singaporean and 73 Taiwanese. However, 20 data were removed from the dataset since they did not pass the attention check, resulting in a total of 111 respondents with 50 Singaporean and 61 Taiwanese. Furthermore, the total number of participants that are accountable for the analysis consists of 48 females (43.2\%) and 63 males (56.8\%). The composition of age includes $2.7 \%$ below 18 years old, $71.2 \%$ from 18 to 25 years old, $6.3 \%$ from 26 to 33 years old, $7.2 \%$ from 34 to 41 years old, and the last one was $12.6 \%$ above 41 years old (Mean $=2.56, S D=1.101$ ).

\section{Procedures and Measurements}

All variables were included in the questionnaire, with three different questions per variable. Age, gender, and nationality of the respondent were asked, while the personal data of the respondents remain anonymous. Before proceeding to the questions, respondents were asked whether they have used Instagram to look for information about local restaurants. To ensure the respondents were paying attention to each question, attention check was incorporated in the questionnaire. The attention check was included within the statements of the last variable by the statement, "For this question, please select disagree". Respondents that did not pass both attention questions were omitted from the dataset.

The measurement scale used was the 7-point Likert scale, ranging from strongly disagree to strongly agree. The statements for each variable were adapted from several prior pieces of literature. Three statements regarding product transparency were adapted from the survey statements of Label Insight Food Revolution Study (2016) about how consumer demand for transparency is shaping the food industry. The statements include "I am aware of where to look for more detailed information about the foods I'm eating.", "I would be willing to choose another local restaurant that shared more detailed food ingredients on Instagram.", and "The local restaurants should be held responsible for providing the complete information about the foods I'm eating there through Instagram.”. While for consumer trust, the statements were adapted from the literature made by Awad and Ragowsky (2008) and Gefen, Karahanna, and Straub (2003). The statements consist of "The Instagram contents of the local restaurants are trustworthy.", "Based on the local restaurants' Instagram contents, I believe they are not opportunistic.", and "I never doubt the honesty of the local restaurants' Instagram contents.".

The UAI will be categorized based on nationality. According to Hofstede, the UAI of Taiwan and Singapore are 69 and 8, respectively (Hofstede, 2001). The variable 'UAI', or the dummy variable, was made in order to categorize the uncertainty avoidance level based on nationality. Therefore, Taiwanese recoded as 1 for 'high' uncertainty avoidance level, while Singaporean recoded as 0 for 'low' uncertainty avoidance level. Age and gender also coded into dummy variables. Since age is a nominal variable, the researcher has recoded the value into 0 for $<34$ years and 1 for $>=34$ years. For gender, the researcher recoded the value by 0 for Male, and 1 for Female.

\section{Reliability Test}

To test the reliability of each variable and to check whether all questions measure in the same direction, the researcher conducted the Cronbach's alpha test. The Cronbach's alpha value is ranging from 0-1; however, only the 
results that are above 0.6 can be summed into one new averaged variable. The Cronbach alpha value for variable Product Transparency is 0.622 , while the value for variable Consumer Trust is 0.626 . Therefore, all three questions for each variable can be summed into two new averaged variables since the Cronbach's alpha value for both variables are still considered acceptable. 'AvPT' was the new averaged variable for product transparency (Mean $=5.17, S D=1.07$ ) and 'AvCT' was the new averaged variable for consumer trust (Mean $=4.24, S D=0.96)$.

\section{RESULTS}

\section{Preliminary Analysis}

The researcher has tested the correlation of each variable by looking at the Pearson correlation coefficient. This method was performed in order to check whether there is a linear relationship between two variables. From the table below, the results of correlation analysis indicate that there are three significant linear relationships, which are the positive relationship between average product transparency and average consumer trust $(r=.306, p<0.01)$, the negative relationship between UAI and consumer trust $(r=-.262, p<0.01)$, and the positive relationship between 'UAI' and 'AvPTxUAI' $(r=.949, p<0.01)$. However, the third correlation was disregarded since it was a relationship between the variable 'UAI' and its interaction term. Since the second correlation was significant, although it was not included in the hypothesis, therefore the researcher would discuss further as additional analysis at the end of this chapter.

Table 1 DESCRIPTIVE STATISTICS AND INTER-CORRELATIONS AMONG VARIABLES

\begin{tabular}{|c|c|c|c|c|c|c|}
\hline Variables & $M$ & $S D$ & (1) & (2) & (3) & (4) \\
\hline AvPT & 5.171 & 1.071 & 1 & & & \\
\hline $\mathrm{AvCT}$ & 4.243 & 0.986 & $.306^{* *}$ & 1 & & \\
\hline UAI & 0.549 & 0.45 & -.132 & $-.262 * *$ & 1 & \\
\hline AvPTxUAI & 2.771 & 2.657 & .121 & -1.86 & $.949 * *$ & 1 \\
\hline
\end{tabular}

$* *$ Correlation is significant at the 0.01 level, $N=111$

\section{Hypothesis Testing}

To test the two hypotheses that already stated in the Theoretical Framework part, linear regression was done to check whether the results can support the hypotheses. Linear regression was chosen for the multivariate analyses for all variables since it only consists of the interval data type. The regression table consists of three different models which can be seen below.

Model 1 is the base model, which only includes the regression analysis of the two control variables, age and gender, with the dependent variable consumer trust. Model 1 is significant since $R^{2}=0.095, F(2,108)=5.693, p=0.004$. Model 2 includes the regression analysis of all control variables and independent variable average product transparency on consumer trust. This model is also significant since $R^{2}=0.190, F(3,107)=8.347, p=0.000$. Moreover, Model 3 includes the regression analysis of all variables, including the moderator 'UAI' and the interaction term 'AvPT x UAI', in order to identify the effect of the moderating variable. Model 3 is significant since $R^{2}=.230, F(5,105)=6.288, p=$ 0.000 . By looking at the adjusted $\mathrm{R}$ squared value of the three models, the researcher can infer that Model 3 has the best model fit since it has the highest adjusted $\mathrm{R}$ squared value.

The age of the respondents has no significant relationship to consumer trust since all of the p-values are higher than 0.5 , and the results were consistent among the three models, which are Model $1(\beta=.022, p>0.05)$, Model $2(\beta=$ $-.042, p>0.05)$, and Model 3 ( $\beta=-.342, p>0.05$ ). However, gender has a negative influence on consumer trust and the results were significant since all of the $p$-values are lower than 0.05 in all of the three models, which are $\beta=-.606$, $p<0.01$ (Model 1), $\beta=-.624, p<0.01$ (Model 2), and $\beta=-.608, p<0.01$ (Model 3). Moreover, by looking at the regression coefficient of gender in all of the three models, it can be inferred that female has a lower intention to trust the content marketing of local restaurants on Instagram rather than male.

The first hypothesis was that product transparency has a positive influence on consumer trust. According to Model 2 and Model 3, the researcher found that product transparency positively influences consumer trust, and the results were consistent among two models, as $\beta>0$ (Model 2: $\beta=0.283, p<0.01$. Model 3: $\beta=0.348, p<0.01$ ). As all of 
the p-values are below 0.01 , therefore the relationship is significant. Therefore, the researcher can reject $\mathrm{H} 0$, and the first hypothesis can be supported.

The second hypothesis was that the higher the UAI, the stronger the influence of product transparency on consumer trust. However, the second hypothesis cannot be supported by Model 3. This model indicates the influence of the interaction variable of average product transparency and UAI (AvPTxUAI) on consumer trust. The results of the regression analysis suggest that there is no significant impact since the p-value is higher than the threshold of 0.05 , with a 95\% confidence level $(\beta=-.135, p>0.05)$. Therefore, $\mathrm{H} 0$ cannot be rejected. The moderation effect of UAI to the influence of product transparency on consumer trust cannot be supported since the results from the regression analysis is not significant.

Table 2 REGRESSION RESULTS ON AVERAGE CONSUMER TRUST (AVCT)

\begin{tabular}{|c|c|c|c|}
\hline Variables & Model 1 & Model 2 & Model 3 \\
\hline Constant & 4.583 & 4.918 & 3.090 \\
\hline Age' & $.022(.236)$ & $-.042(0.225)$ & $-.342(.258)$ \\
\hline Gender' & '-.606*** $(.190)$ & $-.624 * * *(.181)$ & $-.608 * * *(.180)$ \\
\hline Average Product Transparency (AvPT) & - & $0.283 * * *(.080)$ & $.348 * * *(.131)$ \\
\hline UAI", & - & - & $.253(.890)$ \\
\hline AvPTxUAI & - & - & $-.135(.166)$ \\
\hline Observations & 111 & 111 & 111 \\
\hline$F$-statistics & 5.693 & 8.347 & 6.288 \\
\hline Sig. & 0.004 & 0.000 & 0.000 \\
\hline$R^{2}$ & 0.095 & 0.190 & 0.230 \\
\hline Adjusted $R^{2} 0.079$ & 0.167 & 0.194 & \\
\hline \multicolumn{4}{|c|}{ Standard errors in parentheses reported after the regression coefficients (unstandardized). } \\
\hline \multicolumn{4}{|l|}{$* * * p<0.01, * * p<0.05, * p<0.1, N=111$} \\
\hline \multicolumn{4}{|c|}{ 'Dummy coded: $0=<34$ years old, $1 \geq 34$ years old } \\
\hline \multicolumn{4}{|l|}{ "Dummy coded: $0=$ Male, $1=$ Female } \\
\hline "'Dummy coded: $0=$ Low, $1=$ High & & & \\
\hline
\end{tabular}

\section{Additional Analysis}

Table 3 REGRESSION SUMMARY OF UAI WITH CONTROL VARIABLES

\begin{tabular}{|c|c|c|c|c|c|}
\hline \multirow[t]{2}{*}{ Model } & \multicolumn{2}{|c|}{ Unstandardized Coefficients } & \multirow[t]{2}{*}{ Standardized Coefficient } & \multirow[t]{2}{*}{$t$} & \multirow[t]{2}{*}{ Sig. } \\
\hline & $B$ & Std. Error & & & \\
\hline (Constant) & 4.918 & .204 & 24.053 & .000 & \\
\hline Age' & -.325 & .269 & -.132 & -1.207 & .230 \\
\hline Gender" & -.565 & .186 & -.285 & -3.038 & .003 \\
\hline UAI", & -.527 & .212 & -.267 & -2.490 & .014 \\
\hline
\end{tabular}

Dependent Variable $=$ Average Consumer Trust, $N=111$

'Dummy coded: $0=<34$ years old, $1 \geq 34$ years old

"Dummy coded: $0=$ Male, $1=$ Female

"'Dummy coded: $0=$ Low, $1=$ High

Furthermore, the researcher also ran an additional analysis in order to assess the influence of UAI on consumer trust where the control variables, age and gender, are included. As can be seen from the correlation table (see Table 1 in 
Preliminary Analysis), the UAI has a negative relationship with consumer trust. Based on the regression table above, the researcher found that the UAI has a significant negative influence on consumer trust, which can be seen from the Beta value and the $p$-value was below 0.05 ( $\beta=-.527, t=-.2490, p=0.014)$. Therefore, when the UAI higher, consumer trust would become lower.

\section{DISCUSSION}

As stated from the beginning of this research, digital content marketing exists to stimulate the consumer's brand engagement and trust (Hollebeek \& Macky, 2019). However, the scarcity of academic research about digital content marketing might slacken some business owners to obtain the knowledge for utilizing content marketing strategy effectively. Therefore, studies on how to increase the effectiveness of content marketing through social media are needed. This research aims to complement the knowledge in the field of digital content marketing, through examining the influence of product transparency on consumer trust, as well as scrutinizing the moderation effect of uncertainty avoidance level in some particular nationalities such as Taiwanese and Singaporean. The conceptual model that has been discussed previously yielded two hypotheses (see Figure 1). One hypothesis can be supported by the results of the regression analysis regarding the positive influence of product transparency on consumer trust. However, another hypothesis was rejected, on the subject of the moderation effect of UAI to the influence of product transparency on consumer trust.

Consumer trust is very close to the trustworthiness term. The trustworthiness of a business can be judged by the way they promote their product on social media and being truthful about the products offered to consumers. Food and beverage businesses such as local restaurants might embrace their honesty by disclosing their commitment to delivering product transparency. Label Insight Food Revolution Study (2016) confirms that people in this generation are undoubtedly in the midst of a food revolution, which increases the openness of consumers to use several digital channels to access the information regarding the food they are eating. By reflecting on the empirical results, the researcher can imply that product transparency in content marketing is an essential factor in generating consumer trust. This result was consistent with other previous findings from Pan (2014). It was revealed that both the cosmetic and food and beverage industries have a monotony in terms of the consumers perception of product transparency. According to Moser et al. (2012), consumers would like to gather as much information as possible before buying to avoid risk-taking. When they lack product information about specific products, they perceive more risks in buying and consuming such products.

As the moderation effect of the UAI is not significant when product transparency included in the same regression model, therefore it can be inferred that the perceptions about product transparency between respondents from high and low uncertainty avoidance levels are similar although both countries have distinct uncertainty avoidance level. The moderation effect of UAI to the influence of product transparency on consumer trust cannot be accommodated in this research due to several possible reasons.

Firstly, members of uncertainty avoiding cultures might still dare to take risks as long as they believe they know them (Hofstede, 2001). Therefore, this might explain the variability of response about the perception of product transparency, which leads to people who live in high uncertainty avoidance country does not clearly exhibit their behavior to be highly solicited for greater product transparency rather than people who live in a country with lower UAI, because they desire the same matter although they came from different countries with a distinct UAI.

Secondly, the Hofstede UAI was measured by the particular characteristics of cultures. According to Hofstede (1993), people from countries with higher UAI are more intolerant to unconventional behavior and tend to preserve their codes of belief. While for people in weaker UAI countries, they tend to be more tranquil with any unusual behavior and believe that practice is more important than principles. Product transparency is a broad concept that can be implemented both in practice and principles. Being transparent in giving information regarding food products is a denotative instrument for disclosing the ethical principles of businesses. However, they also have to exhibit how ethical principles are implemented in practice and governance (Turilli \& Floridi, 2009). Therefore, this possible reason may lead to a biased distinction between the effect of product transparency on consumer trust in countries with high and low UAI.

By looking at the results of the additional analysis, the UAI still can be a significant predictor to assess the level of consumer trust. From the result of the regression analysis, the UAI negatively influences consumer trust. This result was consistent with the statement made by Chong (2003), who explained that people in a country with higher UAI perceived stronger negative trustworthiness in decision making. In other words, the higher the uncertainty avoidance level of a 
country, the lower the consumer trust towards content marketing. Therefore, this study can still have a contribution to prior academic research such as Brown et al. (2006), by giving the evidence where there is a link between uncertainty avoidance and trust notably in the implication of content marketing.

The potential rationale behind this relationship is that people in high uncertainty avoidance countries try to reduce the perceived risk in a situation, which leads to evidence seeking for their further decisions, while people in low uncertainty avoidance countries have firmer confidence in the abilities of others (Schumann et al., 2007). Doney et al. (1998) suggest that people in high uncertainty avoidance cultures are not likely to engage in opportunistic behavior. Consumer trust, particularly the cognitive one, can be provoked from the integrity, benevolence, and the credibility of a business (Zand, 1972). Therefore, these possible factors might still have a role to affect the level of consumer trust besides product transparency. For example, according to Malthouse, Haenlein, Skiera, Wege, and Zhang (2013), the credibility of a business can be created through developing a platform that enables consumers to give testimonials or reviews on the products, which later could give a shred of real evidence that the business is trustworthy.

Thus, the UAI of a country become one of the cultural dimensions that is still important to be taken into account in order to assess the effectiveness of the content marketing strategy in a specific country. By looking at the UAI, marketers can have the initial hint regarding the propensity of consumers to trust the content marketing of local restaurants on social media. However, this cultural dimension does not have a moderation effect when it comes to the influence of product transparency on consumer trust towards content marketing of local restaurants.

\section{MANAGERIAL IMPLICATIONS}

The main aim of this research was to assess the practicality of content marketing across countries as "cultures differ in their values systems, evaluations of marketing communications will differ" (McCort \& Malhotra, 1993). Although there are many criticisms regarding the Hofstede's theory of cultural dimensions, for example, from a study done by Baskerville (2003), this theory has proven to be valuable for cross-cultural marketing research, when being assessed based on the individual cultural values (e.g., (Schumann et al., 2007)). Therefore, when designing a content marketing strategy for a local restaurant in a specific nation, marketing managers should examine the country's cultural values or dimensions to get the initial view about how consumers would react and trust the content marketing.

The UAI is one of the cultural dimensions that can affect the level of trust beliefs of consumers across countries. In other words, some of the businesses that operate in a higher UAI should take into account any other factors that can affect consumers to trust them because they tend to be more intolerant with unconventional strategies. For example, the credibility of the local restaurant should be depicted in their content marketing. One of the ways to increase the credibility of a local restaurant is to incorporate user-generated content such as testimonials, pictures, and videos from real consumers. Adopting international standards and refusal to adapt to the respective values of different countries, particularly for the design and marketing communications of the services, can be obstacles for business success (Ford et al., 2005).

Marketers of local restaurants should take product transparency into account for their content marketing on all social media, especially Instagram. Being transparent about something that they serve to consumers is one of the steps to increase consumer's propensity to trust. From this research, it can be inferred that transparency is something that people across countries are demanding regardless of whether they come from countries with a high or low uncertainty avoidance level. Product transparency can help to increase the effectiveness of content marketing strategy. For example, local restaurants can provide information about the healthier version of their menu, especially for people with a specific diet such as a low-calorie menu, vegetarian menu, or gluten-free menu. This also can broaden the target market of the local restaurants, so not only general consumers but the consumers with specific diets and allergies could also savor some slightly different kinds of dishes in the same restaurant. Moreover, local restaurants should highlight locally or ethically sourced food, and depicting environmental responsibility such as reducing plastic waste and the use of organic food. Confusion and distrust within consumers can be created due to the lack of transparency in restaurants, which later could prevent them from returning to the same restaurant (Jenkins, 2019).

\section{LIMITATIONS AND FURTHER STUDIES}

This research was only limited to some respondents with the two nationalities, which are Singaporean and Taiwanese. This generates another question regarding external validity, whether the study is also applicable to other nationalities or only bounded to those two nationalities. Moreover, this research was also limited to one social media platform, 
which was Instagram. Different kinds of platform should be incorporated to increase external validity as well. The limitation regarding prior literature was the lack of studies regarding digital content marketing and also a lack of research examining the influence of product transparency on consumer trust. As the sample size was relatively small, this might decrease the statistical power. Increasing the sample size would be interesting since it might increase the validity of the results.

This study was focused only on the food and beverage industry, specifically on local restaurants. Nevertheless, this study could be replicated to other kinds of food and beverage businesses such as big-chain restaurants or packaged foods. Moreover, it would be interesting if the same effect could be verified in other kinds of industries. Even more fundamentally, further research is needed to investigate whether different Hofstede cultural dimensions have a moderating influence on the cognitive consumer trust-building processes. Moreover, analyzing more countries with various uncertainty avoidance levels should be beneficial to verify whether these results can be replicated in other countries. Since one of the control variables, gender, has a significant effect on consumer trust in all of the three models, therefore further studies regarding this factor are needed in order to gain a better understanding of the difference between female and male propensity to trust towards content marketing on social media.

\section{CONCLUSION}

To conclude, this study aimed to examine the influence of product transparency on consumer trust towards content marketing of local restaurants on Instagram, and also the moderating role of UAI. The valid respondents of the survey were 50 Singaporean and 61 Taiwanese. It was verified that the product transparency has a positive influence on consumer trust. However, the moderating role of UAI to the influence of product transparency on consumer trust cannot be supported by this research since product transparency is considered important regardless whether the consumers come from high or low uncertainty avoidance country. Therefore, providing transparent information regarding food products or menus in content marketing would help to increase the effectiveness of local restaurant's marketing strategy through social media. Moreover, an additional analysis generated the evidence that UAI has a negative influence on consumer trust. The adaptation of marketing communications across countries is needed since the UAI of a country also predicts the tendency of consumers to trust a business's content marketing in social media. Furthermore, surveying in the first place about the cultural dimensions of where the business operates should be beneficial for local restaurant marketers to recognize the consumer's propensity to trust the content marketing strategy. This study can be extended by including more nationalities for the analysis to ensure whether it can be replicated across countries and other kinds of food and beverage businesses should be further investigated.

\section{REFERENCES}

Arnott, D. C., \& Wilson, D. (2007). Trust-current thinking and future research. European Journal of Marketing, 41(9/10), 981-987. doi:https://doi.org/10.1108/03090560710773291

Arnott, D. C., Wilson, D., \& Sichtmann, C. (2007). An analysis of antecedents and consequences of trust in a corporate brand. European Journal of Marketing, 41(9/10), 999-1015. doi:https://doi.org/10.1108/03090560710773318

Australian Academy of Science. (n.d). The chemistry of cosmetics. Retrieved from https://bit.ly/3ceggHv

Awad, N. F., \& Ragowsky, A. (2008). Establishing trust in electronic commerce through online word of mouth: An examination across genders. Journal of Management Information Systems, 24(4), 101-121. doi:https://doi.org/ 10.2753/mis0742-1222240404

Baker, P., \& Friel, S. (2016). Food systems transformations, ultra-processed food markets and the nutrition transition in Asia. Globalization and Health, 12(1), 1-15. doi:https://doi.org/10.1186/s12992-016-0223-3

Baskerville, R. F. (2003). Hofstede never studied culture. Accounting, Organizations and Society, 28(1), 1-14. doi:https://doi.org/10.1016/s0361-3682(01)00048-4

Benjamin, D. (2018). The naked restaurant: Restaurants bare all in move to transparency. Retrieved from https:// bit.ly/3duRqUi

Bilog, D. Z. (2017). Investigating consumer preferences in selecting buffet restaurants in Davao region, Philippines. Journal of Administrative and Business Studies, 3(5), 221-233. doi:https://doi.org/10.20474/jabs-3.5.2

Brown, I., Field, B., A. adn Hill, \& Wessels, G. (2006). The role of uncertainty avoidance and trust in online shopping adoption. In 8th Annual Conference on WWW Applications, South Africa. 
Chen, M.-F. (2008). Consumer trust in food safety-a multidisciplinary approach and empirical evidence from Taiwan. Risk Analysis: An International Journal, 28(6), 1553-1569. doi:https://doi.org/10.1111/j.1539-6924.2008.01115 .X

Chong, B. (2003). Why culture matters for the formation of consumer trust? A conceptual study of barriers for realizing real global exchange in Hong Kong. Asia Pacific Management Review, 8(2).

Doney, P. M., Cannon, J. P., \& Mullen, M. R. (1998). Understanding the influence of national culture on the development of trust. Academy of Management Review, 23(3), 601-620. doi:https://doi.org/10.5465/amr.1998.926629

Doyle, V. (2019). Why brand trust needs to guide your content marketing strategy. Retrieved from https://bit.ly/ 2WQGmtZ

Du Plessis, C. (2015). Academic guidelines for content marketing: Research-based recommendations for better practice. Retrieved from https://bit.ly/2yEhKfB

English First. (2019). English proficiency index. Retrieved from https://www.ef.com/wwen/epi/

Ford, J. B., Malhotra, N. K., Ulgado, F. M., Agarwal, J., Shainesh, G., \& Wu, L. (2005). Dimensions of service quality in developed and developing economies: Multi-country cross-cultural comparisons. International Marketing Review, 22(3), 256-278. doi:https://doi.org/10.1108/02651330510602204

Gartner L2. (2014). Instagram 2014. Retrieved from https://bit.ly/3dx1qMq

Gefen, D., Karahanna, E., \& Straub, D. W. (2003). Trust and tam in online shopping: An integrated model. MIS Quarterly, 27(1), 51-90. doi:https://doi.org/10.2307/30036519

Granados, N., Gupta, A., \& Kauffman, R. J. (2010). Research commentary-information transparency in business-toconsumer markets: Concepts, framework, and research agenda. Information Systems Research, 21(2), 207-226. doi:https://doi.org/10.1287/isre.1090.0249

Green Hasson \& Janks. (2013). Social media in the food and beverage industry. Retrieved from https://bit.ly/3cjdUHo

Hamadeh, S. (2017). Digital food marketing: What we know, what we should know? British Journal of Marketing Studies, 5(8), 12-26.

Haselhuhn, M. P., Kennedy, J. A., Kray, L. J., Van Zant, A. B., \& Schweitzer, M. E. (2015). Gender differences in trust dynamics: Women trust more than men following a trust violation. Journal of Experimental Social Psychology, 56, 104-109. doi:https://doi.org/10.1016/j.jesp.2014.09.007

Hofstede, G. (1984). Culture's consequences: International differences in work related values. Beverly Hills, CA: Sage Publications.

Hofstede, G. (1993). Cultural constraints in management theories. Academy of Management Perspectives, 7(1), 81-94. doi:https://doi.org/10.5465/ame.1993.9409142061

Hofstede, G. (2001). Culture's consequences: Comparing values, behaviors, institutions and organizations across nations. Thousand Oaks, CA: Sage Publications.

Hollebeek, L. D., \& Macky, K. (2019). Digital content marketing's role in fostering consumer engagement, trust, and value: Framework, fundamental propositions, and implications. Journal of Interactive Marketing, 45, $27-41$. doi:https://doi.org/10.1016/j.intmar.2018.07.003

Hustvedt, G., \& Kang, J. (2013). Consumer perceptions of transparency: A scale development and validation. Family and Consumer Sciences Research Journal, 41(3), 299-313. doi:https://doi.org/10.1111/fcsr.12016

Jenkins, R. (2019). Food transparency in restaurants. Retrieved from https://bit.ly/35LugpV

Johnson, D., \& Grayson, K. (2005). Cognitive and affective trust in service relationships. Journal of Business Research, 58(4), 500-507. doi:https://doi.org/10.1016/s0148-2963(03)00140-1

Jones, K. (2016). Why food industry transparency matters to restaurant guests. Retrieved from https://bit.ly/2SOG9WZ

Kang, C. Z., \& Ogawa, I. (2017). Online shopping behavior of chinese and japanese consumers. Journal of Administrative and Business Studies, 3(6), 305-316. doi:https://doi.org/10.20474/jabs-3.6.5

Kearney, J. (2010). Food consumption trends and drivers. Philosophical Transactions of the Royal Society B: Biological Sciences, 365(1554), 2793-2807.

Kee, A. W. A., \& Yazdanifard, R. (2015). The review of content marketing as a new trend in marketing practices. International Journal of Management, Accounting and Economics, 2(9), 1055-1064.

Kim, D. J., Ferrin, D. L., \& Rao, H. R. (2008). A trust-based consumer decision-making model in electronic commerce: The role of trust, perceived risk, and their antecedents. Decision Support Systems, 44(2), 544-564. doi:https://doi.org/10.1016/j.dss.2007.07.001 
Kitdumrongthum, N., \& Thechatakerng, P. (2018). Product innovation's determinants of Chinese family business in Chiangmai and consumer socioeconomics. International Journal of Business and Economic Affairs, 3(3), 141-146. doi:https://doi.org/10.24088/ijbea-2018-33005

Label Insight Food Revolution Study. (2016). How consumer demand for transparency is shaping the food industry. Retrieved from https://bit.ly/3cidmS1

Lambert-Pandraud, R., \& Laurent, G. (2010). Why do older consumers buy older brands? The role of attachment and declining innovativeness. Journal of Marketing, 74(5), 104-121. doi:https://doi.org/10.1509/jmkg.74.5.104

Lee, H.-G. (1998). Do electronic marketplaces lower the price of goods? Communications of the ACM, 41(1), 73-80. doi:https://doi.org/10.1145/268092.268122

Liu, S., Jiang, C., Lin, Z., Ding, Y., Duan, R., \& Xu, Z. (2015). Identifying effective influencers based on trust for electronic word-of-mouth marketing: A domain-aware approach. Information Sciences, 306, 34-52. doi:https:// doi.org/10.1016/j.ins.2015.01.034

Local Saute. (n.d.). What is an independent restaurant? Retrieved from https://bit.ly/2LdXHaB

Malthouse, E. C., Haenlein, M., Skiera, B., Wege, E., \& Zhang, M. (2013). Managing customer relationships in the social media era: Introducing the social crm house. Journal of Interactive Marketing, 27(4), 270-280. doi:https://doi.org/10.1016/j.intmar.2013.09.008

McCort, D. J., \& Malhotra, N. K. (1993). Culture and consumer behavior: Toward an understanding of cross-cultural consumer behavior in international marketing. Journal of International Consumer Marketing, 6(2), 91-127. doi:https://doi.org/10.1300/j046v06n02_07

Moorman, C., Zaltman, G., \& Deshpande, R. (1992). Relationships between providers and users of market research: The dynamics of trust within and between organizations. Journal of Marketing Research, 29(3), 314-328. doi:https://doi.org/10.1177/002224379202900303

Moser, R., Schaefers, T., \& Meise, J. N. (2012). Consumer preferences for product transparency in emerging markets-lessons learned from India. Marketing Review St. Gallen, 29(3), 22-27. doi:https://doi.org/10.1365/ s11621-012-0133-6

Newman, D. (2014). 5 steps to build trust using content marketing. Retrieved from https://bit.ly/3ctFBgE

Pan, S. (2014). The effect of product transparency on female consumers' loyalty towards cosmetics brands. Master thesis, University of Amsterdam, Amsterdam, Netherlands.

Pheng, L. S., \& Yuquan, S. (2002). An exploratory study of Hofstede's cross-cultural dimensions in construction projects. Management Decision, 40(1), 7-16. doi:https://doi.org/10.1108/00251740210423036

Polevikova, M. (2013). Business environment in Singapore. Bachelor's thesis, Saimaa University of Applied Science, Finland, South Karelia.

Pulizzi, J., \& Handley, A. (2014). B2C content marketing 2014: Benchmarks, budgets, and trends-North America. Retrieved from https://bit.ly/2WDBKXT

Rampl, L. V., Eberhardt, T., Schütte, R., \& Kenning, P. (2012). Consumer trust in food retailers: Conceptual framework and empirical evidence. International Journal of Retail \& Distribution Management, 40(4), $254-272$. doi:https://doi.org/10.1108/09590551211211765

Rempel, J. K., Holmes, J. G., \& Zanna, M. P. (1985). Trust in close relationships. Journal of Personality and Social Psychology, 49(1), 95-112. doi:https://doi.org/10.1037/e629682009-001

Rowley, J. (2008). Understanding digital content marketing. Journal of Marketing Management, 24(5-6), 517-540. doi:https://doi.org/10.1362/026725708x325977

Schumann, J. H., Wangenheim, F., Yang, Z., Jinenez, F., Komor, M., Praxmarer, S., \& Shainesh, G. (2007). Crosscultural differences in the development of trust in relational service exchange-an empirical analysis of the moderating role of uncertainty avoidance. Brussels, Belgium: The European Institute for Advanced Studies in Management (EIASM).

The Hartman Group. (2015). Why transparency should matter to food and beverage companies. Retrieved from https://bit.ly/3dpgsUs

Trappey, C. V., Trappey, A. J., \& Mulaomerovic, E. (2016). Improving the global competitiveness of retailers using a cultural analysis of in-store digital innovations. International Journal of Technology Management, 70(1), 25-43.

Tsai, W. (2009). The culture differences on web design: A study of Taiwan's and United States' websites. Graduate theses, Iowa State University, Ames, IA. 
Turilli, M., \& Floridi, L. (2009). The ethics of information transparency. Ethics and Information Technology, 11(2), 105-112. doi:https://doi.org/10.1007/s10676-009-9187-9

Walter. (2015). Content marketing for food and beverage business. Retrieved from https://bit.ly/3chTVcf

Zand, D. E. (1972). Trust and managerial problem solving. Administrative Science Quarterly, 17(2), $229-239$. doi:https://doi.org/10.2307/2393957 